\title{
Synthesis, Characterization and Enhanced visible light induced photocatalytic activity of $\mathrm{NiO} / \mathrm{g}-\mathrm{C}_{3} \mathrm{~N}_{4}$ nanocomposite
}

\section{Gayathri}

SRM Institute of Science and Technology

N. Jayaprakssh

Valliammai Engineering College

Sundaravadivel E ( $\nabla$ sundaravadivelchem@gmail.com )

SRM University https://orcid.org/0000-0003-0209-6192

\section{Research Article}

Keywords: Binary composite, graphitic carbon nitride, NiO, rhodamine B

Posted Date: March 17th, 2021

DOI: https://doi.org/10.21203/rs.3.rs-298371/v1

License: (c) (1) This work is licensed under a Creative Commons Attribution 4.0 International License. Read Full License 


\section{Abstract}

Heterogeneous binary nanocomposite based photocatalysis is a potential strategy to resolve the worldwide ecological issues. Here, graphitic carbon nitride $\left(\mathrm{g}-\mathrm{C}_{3} \mathrm{~N}_{4}\right)$ containing NiOnanocomposite (NC) was synthesized by simple mixing. Pure $\mathrm{NiO}$ and $\mathrm{g}-\mathrm{C}_{3} \mathrm{~N}_{4}$ was synthesised by hydrothermal and thermal decomposition methods respectively. As synthesized g- $\mathrm{C}_{3} \mathrm{~N}_{4}, \mathrm{NiO}$, and $\mathrm{NiO} / \mathrm{g}-\mathrm{C}_{3} \mathrm{~N}_{4}$, composite were characterized by XRD, FTIR, UV-vis spectroscopy, FE-SEM, and HR-TEM. NiO nanoparticles were uniformly distributed on $\mathrm{C}_{3} \mathrm{~N}_{4}$ matrix. Photocatalytic degradation of Rhodamine $\mathrm{B}(\mathrm{RhB})$ was investigated under visible light irradiation. The results confirm that $81 \%$ of $\mathrm{RhB}$ was degraded within 60 min under $\mathrm{NiO} / \mathrm{g}$ $\mathrm{C}_{3} \mathrm{~N}_{4}$ visible light system. This study suggests that potential in environmental applications.

\section{Introduction}

Recently most of the chemical industries using several toxic substances such as chlorophenols, heavy metals, dioxins, polychlorinated biphenyls, asbestos, and dyes as in the form of solvents, and active ingredients for preparation of products [1]. After completion of chemical process, they are let out through our environment [2]. These toxic chemicals cause severe health issues in human beings such as skin infection, cancer, nervous problem, and waterborne disease [3].Even aquatic and terrestrial animals also affected and it reflects in ecological imbalance. Dyes are unavoidable necessary materials for our lifestyle. Nowadays, rhodamine $\mathrm{B}(\mathrm{RhB})$ is a widely used dye in medicine, biological staining, painting, printing, food, and leather industries [4]. It has highly colorant which leads to the carcinogenic/mutagenic to the living organisms [5]. RhB has a diminution of the light diffusion in water which reduces aquatic species photosynthesis and natural water purification [6]. Hence, RhB removal is very important from the environment water/industrial wastewater before deteriorating in the ecosystem.

Several methods such as adsorption, reverse osmosis, ion exchange, and biological methods were employed to the removal of RhB [7]. Photocatalytic degradation of dye molecules is one of the best methods compare to other techniques [8]. In photocatalysis, many of the semiconductors like zinc oxide $(\mathrm{ZnO})$, tungsten oxide $\left(\mathrm{WO}_{3}\right)$, strontium titanate $\left(\mathrm{SrTiO}_{3}\right)$, and titanium dioxide $\left(\mathrm{TiO}_{2}\right)$ are acted as dynamic photocatalysts [9-12]. Among others, NiOis one of the semiconducting materials. It has a better chemical stability and adsorption property [13]. However, NiO has less absorption in the visible region and also limits the photocatalytic efficiency $[14,15]$.

On the other hand, $\mathrm{g}-\mathrm{C}_{3} \mathrm{~N}_{4}$ is a chemically stable and non-hazardous metal free semiconductor photocatalyst. Because, it has a band gap of $2.8 \mathrm{eV}$ [16], which is responsible to absorb visible light region and it was suggested to be the best option to produce nano heterostructure. Moreover, g- $\mathrm{C}_{3} \mathrm{~N}_{4}$ can be easily synthesized by using economically available precursors such as urea, melamine, cyanamide, and thiourea [17]. Though, $\mathrm{NiO}$ acts as a photocatalyst, the efficiency is low as compared with the $\mathrm{g}-\mathrm{C}_{3} \mathrm{~N}_{4}$ [18].Generally, bare metal oxides has some limitations regarding the charge separation and difficult to transfer and participate redox reaction [19]. To overcome this limitation, it is necessary to prepare new Loading [MathJax]/jax/output/CommonHTML/jax.js 
composites to further improve the photocatalytic efficiency of dye degradation [20-21]. Hence, combination of $\mathrm{NiO}$ and $\mathrm{g}-\mathrm{C}_{3} \mathrm{~N}_{4}$ could attain the efficient visible-light-driven photocatalytic activity without any additional oxidant [22]. For example, recently, reported composite like $\mathrm{MgO}-\mathrm{g}-\mathrm{C}_{3} \mathrm{~N}_{4}, \mathrm{ZnO} / \mathrm{g}$ $\mathrm{C}_{3} \mathrm{~N}_{4}, \mathrm{MnO}_{2}-\mathrm{g}-\mathrm{C}_{3} \mathrm{~N}_{4}$ performed outstanding photocatalytic activity than their corresponding single entity [23-27]. In the present study $\mathrm{NiO} / \mathrm{g}-\mathrm{C}_{3} \mathrm{~N}_{4}$, nanocomposite was synthesized by the simple mixing method and applied as photocatalyst to the RhBphoto degradation reaction assisted with visible light illumination.

\section{Materials And Methods \\ 2.1. Reagents required}

Nickel acetate tetrahydrate, sodium hydroxide, rhodamine B and urea were purchased from Sigma-Aldrich (India) and used as received. Distilled water was used as solvent for the whole experiments.

\subsection{Synthesis of $\mathrm{g}-\mathrm{C}_{3} \mathrm{~N}_{4}$}

The $\mathrm{g}-\mathrm{C}_{3} \mathrm{~N}_{4}$ sheets were synthesized by the direct decomposition method [28]. By this method, $5 \mathrm{~g}$ of urea were taken in a silica crucible covered with a lid and it was kept into the muffle furnace (JOTHI) up to 550 ${ }^{\circ} \mathrm{C}$ for about $4 \mathrm{~h}$.

\subsection{Synthesis of NiO-NP}

$\mathrm{NiO}$ was synthesized by the hydrothermal method. $20 \mathrm{ml}$ of $1 \mathrm{M}$ nickel acetate tetrahydrate aqueous solution was taken and stirred till dissolved and then $20 \mathrm{ml}$ of $0.5 \mathrm{M}$ of aqueous sodium hydroxide solution was added dropwise under vigorous stirring which forms green color nickel hydroxide precipitate. Further, the suspension was transferred into a $50 \mathrm{ml}$ capacity of Teflon-lined autoclave and maintained a temperature of $120^{\circ} \mathrm{C}$ over $6 \mathrm{~h}$. Then the obtained precipitate was washed with water and ethanol. Finally, the dried powder was calcined at $400{ }^{\circ} \mathrm{C}$ up to $4 \mathrm{~h}$ thus forming nickel oxide nanoparticles.

\subsection{Preparation of $\mathrm{NiO}-\mathrm{g}-\mathrm{C}_{3} \mathrm{~N}_{4}$}

The $80 \mathrm{mg}$ of $\mathrm{NiO}$ was dispersed in $50 \mathrm{~mL}$ of distilled water. Then $20 \mathrm{mg}$ of $\mathrm{g}-\mathrm{C}_{3} \mathrm{~N}_{4}$ was dispersed in 50 $\mathrm{mL}$ of de-ionized water separately. $\mathrm{g}-\mathrm{C}_{3} \mathrm{~N}_{4}$ dispersion was added to $\mathrm{NiO}$ aqueous dispersion under constant stirring up to 2 hours. Afterward, it was washed with ethanol and water several times and dried at $70^{\circ} \mathrm{C}$ over night to obtain NiO-gC $\mathrm{C}_{3} \mathrm{~N}_{4}$ nanocomposite.

\subsection{Characterization techniques}

The crystalline nature of the synthesized material was studied by powder $X$-ray diffraction (PAN analytical) with Cu Ka radiation at a voltage of $40 \mathrm{kV}$. Fourier transform infrared spectra were recorded by IR tracer 500, the surface morphology and elemental composition were identified by field emission 
coupled with EDS. The transmission electron microscopic (TEM) images were captured by using a JEOL, JEM, Fb-2000 instrument at an accelerating voltage of $200 \mathrm{kV}$. The UV-Vis (AGINITY 5000) diffuse reflectance spectroscopy using $\mathrm{BaSO}_{4}$ as a reference was used to determine the optical property of samples.

\subsection{Dye degradation test}

Photocatalytic property of bare $\mathrm{NiO}, \mathrm{g}-\mathrm{C}_{3} \mathrm{~N}_{4}$, and their binary nanocomposites was studied by using the model of RhB pollutant under visible light irradiation. First, $10 \mathrm{mg}$ of RhB was dissolved in $100 \mathrm{~mL}$ of distilled water in addition to that $100 \mathrm{mg}$ of the synthesized sample were added and kept in constant stirring up to $1 \mathrm{~h}$ to get an equilibrium solution. Finally, the solution was placed under visible light irradiation to get the solution at every 10 minutes intervals. Each sample was filtered and analyzed through UV Visible absorption spectroscopy. The decolurization efficiency was calculated by using the equation (s).

$$
\% \text { ofDecolourisation }=\frac{C_{0-} C_{1}}{C_{0}} \times 100
$$

1

Here, $C_{0}$ is the initial concentration of the RhB dye solution; $C_{1}$ is the concentration of the dye solution at various time intervals under visible-light irradiation [29-30].

\section{Results And Discussion}

\subsection{Physicochemical studies}

Figure 2 (a-c) shows the XRD pattern of $\mathrm{NiO}, \mathrm{g}-\mathrm{C}_{3} \mathrm{~N}_{4}$ and $\mathrm{NiO} / \mathrm{g}-\mathrm{C}_{3} \mathrm{~N}_{4}$. The $\mathrm{NiO}$ diffraction peaks at $37.0^{\circ}$, $43.2^{\circ}, 62.4^{\circ}, 75.4^{\circ}$ and $79.3^{\circ}$ corresponding to the reflective planes of (111), (200), (220), (311) and (222), respectively. This result is well-matched with the JCPDS card no-04-0835. These diffraction peaks are perfectly indexed with face-centered cubic phase crystalline structure of $\mathrm{NiO}$ (Fig. 2a) [31]. The diffraction peaks exist at $13.4^{\circ}$ and $27.4^{\circ}$ which corresponds to (100), and (002) planes of bare g- $\mathrm{C}_{3} \mathrm{~N}_{4}$ (JCPDS card No-65-287), These peaks are attributed to interplanar staking of aromatic systems along with inter-layer structural packing represented in Fig. 2(b) [32].After the addition of $\mathrm{g}-\mathrm{C}_{3} \mathrm{~N}_{4}$ into $\mathrm{NiO}$ the diffraction peak intensity of NiOwas increased (Fig. 2c). Moreover a minor peak appeared at 27.4\ confirms the presence of $\mathrm{g}-\mathrm{C}_{3} \mathrm{~N}_{4}$ in the composite material. It may occur due to dominant of diffraction peak of $\mathrm{NiO}$ [33].

FTIR spectrum (Fig. 3a) of bare NiO exhibits the peak at $833 \mathrm{~cm}^{-1}$ which is assigned to Ni-O [34], The peak, $1352 \mathrm{~cm}^{-1}$ is assigned to symmetric and asymmetric stretching vibration of $\mathrm{O}-\mathrm{C}=0,1636 \mathrm{~cm}^{-1}$ assigned to $\mathrm{H}-\mathrm{O}-\mathrm{H}$ bending vibration, $2342 \mathrm{~cm}^{-1}$ assigned to $\mathrm{CO}_{2}$ mode, peak formed around $3459 \mathrm{~cm}^{-1}$ indicates the presence of water molecule even after calcination of NiO [35]. Figure 3b shows the FTIR $805 \mathrm{~cm}^{-1}$ due to bending vibration mode of triazine units, 
and numerous band appeared at $1277 \mathrm{~cm}^{-1}, 1321,1558,1634$ could be assigned to $\mathrm{C}-\mathrm{N}, 3184 \mathrm{~cm}^{-1}$ indicates $\mathrm{O}-\mathrm{H}$ bond [36]. Finally we compare with binary $\mathrm{NiO} / \mathrm{g}-\mathrm{C}_{3} \mathrm{~N}_{4}$ nanocomposite exhibits absorption band similar to bare g- $\mathrm{C}_{3} \mathrm{~N}_{4}$. After the doping of $\mathrm{NiO}$ with $\mathrm{g}-\mathrm{C}_{3} \mathrm{~N}_{4}$, the spectrum does not show any other vibration peak and the corresponding peaks were indicates the pure phases of $\mathrm{NiO}$ and $\mathrm{g}-\mathrm{C}_{3} \mathrm{~N}_{4}$, confirms the formation of $\mathrm{NiO} / \mathrm{g}-\mathrm{C}_{3} \mathrm{~N}_{4}$ nanocomposite.

\section{Optical studies}

Optical absorption behavior of the synthesized bare $\mathrm{NiO}, \mathrm{g}-\mathrm{C}_{3} \mathrm{~N}_{4}$ and $\mathrm{NiO} / \mathrm{g}-\mathrm{C}_{3} \mathrm{~N}_{4}$, was evaluated by DRS UV-Vis spectroscopy (Fig. 4A (a-c). Bare NiO exhibits a strong absorption in Uv and visible region and bare $\mathrm{g}-\mathrm{C}_{3} \mathrm{~N}_{4}$ exhibits the absorbance edge at $470 \mathrm{~nm}$ respectively. Then we analyze $\mathrm{NiO} / \mathrm{g}-\mathrm{C}_{3} \mathrm{~N}_{4}$ composite that exhibits the absorption edge as same as bare $\mathrm{NiO}$ due to the highest loading of $\mathrm{NiO}$ in $\mathrm{NiO} / \mathrm{g}-\mathrm{C}_{3} \mathrm{~N}_{4}$ composite. The band gap value of the bare and binary nanocomposite was also evaluated by Tauc's plot method

$$
(\alpha h v) 2=C(h \nabla-E g)
$$

Here $\mathrm{a}$ is a light absorption coefficient, $\mathrm{h}$ is a plank constant, $\mathrm{v}$ is a light frequency, $\mathrm{C}$ is a velocity of light, $E_{g}$ is band gap energy. The band gap values of bare $\mathrm{NiO}, \mathrm{g}-\mathrm{C}_{3} \mathrm{~N}_{4}$ and $\mathrm{NiO} / \mathrm{g}-\mathrm{C}_{3} \mathrm{~N}_{4}$ andwere $2.67 \mathrm{eV}, 2.86 \mathrm{eV}$ and 2.45 eVis given in Fig.4B(a-c) respectively. The band gap energy of $\mathrm{NiO} / \mathrm{g}-\mathrm{C}_{3} \mathrm{~N}_{4}$ is lower than that of bare $\mathrm{NiO}$ and $\mathrm{g}-\mathrm{C}_{3} \mathrm{~N}_{4}$ indicate the absorption of $\mathrm{NiO} / \mathrm{g}-\mathrm{C}_{3} \mathrm{~N}_{4}$ nanocomposite is shifted towards lower energy region[37]

\subsection{FESEM and HRTEM}

Morphological observations of as prepared bare NiO, bare g- $\mathrm{C}_{3} \mathrm{~N}_{4}$ and $\mathrm{NiO} / \mathrm{g}-\mathrm{C}_{3} \mathrm{~N}_{4}$ was done by scanning electron microscope coupled with EDS. FESEM images (Fig. 5a-c) of bare $\mathrm{NiO}$ exhibit spherical shape which results in enough rough surface and large specific surface area and active adsorption sites.[38] Furthermore bare NiO was characterized by HRTEM and the obtained images are given in Fig. 5.(d \& e). It could observe an agglomerated spherical morphology which was consistent with SEM results. Figure 5(f) shows the SAED pattern of bare NiO.

Fig. $6(a, b)$ shows the FESEM images of bare $g-C_{3} N_{4}$ which exhibits sheet like morphology and contains some wrinkles on it. Further, sheet like morphology of as prepared bare $\mathrm{g}-\mathrm{C}_{3} \mathrm{~N}_{4}$ was investigated by high resolution transmission electron microscopic technique (Fig.6 c,d). The observed images were exfoliated $\mathrm{g}-\mathrm{C}_{3} \mathrm{~N}_{4}$ nanosheets which has highly light transmittance features might reflects ultrathin layered structure [39].

While the preparation of $\mathrm{NiO} / \mathrm{g}-\mathrm{C}_{3} \mathrm{~N}_{4}$ composite,NiO NP's was successfully deposited over the surface of $\mathrm{g}-\mathrm{C}_{3} \mathrm{~N}_{4}$ nanosheets. Figure 7(a) represents FESEM image of $\mathrm{NiO} / \mathrm{g}-\mathrm{C}_{3} \mathrm{~N}_{4}$ composite. It exhibits an Loading [MathJax]/jax/output/CommonHTML/jax.js re which enhances the absorption capacity of the dye. It 
could further increase the photocatalytic activity of the composite material [40]. Moreover, the HRTEM image of $\mathrm{NiO} / \mathrm{g}-\mathrm{C}_{3} \mathrm{~N}_{4}$ shows that spherical $\mathrm{NiO}$ nanoparticles are evenly distributed on the surface of $\mathrm{g}$ $\mathrm{C}_{3} \mathrm{~N}_{4}$ nanosheets (Fig. 7b). EDS spectrum of $\mathrm{NiO} / \mathrm{g}-\mathrm{C}_{3} \mathrm{~N}_{4}$ composite (Fig. 7c) indicates the corresponding peaks confirms $\mathrm{C}, \mathrm{N}, \mathrm{O}$ and $\mathrm{Ni}$ elements were present in the $\mathrm{NiO} / \mathrm{g}-\mathrm{C}_{3} \mathrm{~N}_{4}$ nanocomposite [41].

\subsection{Photo catalytic performance}

Photo catalytic activity of bare $\mathrm{NiO}, \mathrm{g}-\mathrm{C}_{3} \mathrm{~N}_{4}$, and $\mathrm{NiO} / \mathrm{g}-\mathrm{C}_{3} \mathrm{~N}_{4}$ nanocomposites was carried out by visible light irradiation. It is noteworthy that the $\mathrm{RhB}$ was degraded up to $81 \%$ after $60 \mathrm{~min}$ in presence of $\mathrm{NiO} / \mathrm{g}$ $\mathrm{C}_{3} \mathrm{~N}_{4}$ nanocomposite. While, bare $\mathrm{NiO}$ and $\mathrm{g}-\mathrm{C}_{3} \mathrm{~N}_{4}$, photocatalyst exhibits $73 \%$ and $75 \%$ of efficiency (Fig. 8 (a-c)). A photocatalytic activity of these materials was elucidated by kinetic studies and decomposition rate is calculated by pseudo first order kinetic equation [42-43]. In the present work, a feasible mechanism of the enhanced photocatalytic activity of $\mathrm{g}-\mathrm{C}_{3} \mathrm{~N}_{4} / \mathrm{NiO}$ nanocomposite was associated with the efficient absorbance of visible light and effective separation of electron-hole pairs. The $\mathrm{g}-\mathrm{C}_{3} \mathrm{~N}_{4}$ and $\mathrm{NiO}$ band edge positions are calculated using the below equations

$$
\begin{gathered}
E_{V B}=X-E_{C}+0.5 E_{g} \\
E_{C B}=E_{V B}-E_{g}
\end{gathered}
$$

Where, $\mathrm{E}_{\mathrm{VB}}, \mathrm{E}_{\mathrm{CB}}, \mathrm{X}$, and $\mathrm{E}_{\mathrm{g}}$ have represented the valance band (VB), conduction band (CB) potentials, Mulliken's electronegativity of semiconductor, and energy band gap respectively. The $X$ values for $\mathrm{g}-\mathrm{C}_{3} \mathrm{~N}_{4}$ and $\mathrm{NiO}$ are calculated to be 4.73 and 5.76 respectively [44-47]. As per the above equations the calculated $\mathrm{VB}, \mathrm{CB}$ values for $\mathrm{g}-\mathrm{C}_{3} \mathrm{~N}_{4}\left(\mathrm{E}_{\mathrm{VB}} 1.43 \mathrm{eV}, \mathrm{E}_{\mathrm{CB}}-0.97 \mathrm{eV}\right)$, NiO $\left(\mathrm{E}_{\mathrm{VB}} 2.79 \mathrm{eV}, \mathrm{E}_{\mathrm{CB}}-0.27 \mathrm{eV}\right)$, respectively, and the band gap energies were calculated by Tauc's-plot. According to the calculated band edge value positions of $\mathrm{g}-\mathrm{C}_{3} \mathrm{~N}_{4}$ and $\mathrm{NiO}$, the band arrangement of composite with a charge transfer mechanism were also evaluated.

The kinetic studies were elucidated in Fig. 9A feasible mechanism of the enhanced photo catalytic activity of $\mathrm{gC}_{3} \mathrm{~N}_{4} / \mathrm{NiO}$ nanocomposite was associated with the efficient absorbance of visible light and separation of electron hole pairs. After the irradiation of $\mathrm{g}-\mathrm{C}_{3} \mathrm{~N}_{4}$ using visible light $(\lambda>420 \mathrm{~nm})$, the conduction band potential of $E_{C B}=-0.97 \mathrm{~V}$ vs RHE g- $\mathrm{C}_{3} \mathrm{~N}_{4}$ could easily absorb visible light further generate electrons/pairs. Generally the photo-induced electron-hole pairs again recombined with bare $\mathrm{g}-\mathrm{C}_{3} \mathrm{~N}_{4}$. This results of bare $\mathrm{g}-\mathrm{C}_{3} \mathrm{~N}_{4}$ is unsatisfied the degradation reaction mechanism. Further improve the efficiency of bare $\mathrm{g}-\mathrm{C}_{3} \mathrm{~N}_{4}$ is mixing with NiO NP's and formation of $\mathrm{NiO} / \mathrm{g}-\mathrm{C}_{3} \mathrm{~N}_{4}$ nanocomposites. This nanocomposite prevents the recombination of electrons and holes. The interaction of photogenerated electrons and holes would react with oxygen and water to generate superoxide radicals $\left(\cdot \mathrm{O}_{2}{ }^{-}\right)$and $(\cdot \mathrm{OH})$ radicles. Therefore holes present in the valence band of NiOand surface of the $\mathrm{g}-\mathrm{C}_{3} \mathrm{~N}_{4}$ may also reacts with $\mathrm{H}_{2} \mathrm{O}$ to form new $\cdot \mathrm{OH}$ radicals which have a capacity to oxidize dye molecules. From the whole, these radicals and electrons which is remain in the $\mathrm{g}-\mathrm{C}_{3} \mathrm{~N}_{4}$ conduction band reacts with oxygen to 
generate reactive superoxide radicals $\left(\cdot \mathrm{O}_{2}-\right)$ and they reacts with water through the stepwise reduction of $\mathrm{O}_{2}$ to produce $\cdot \mathrm{OH}$ radicals. Thus increases the spatial separation of electron hole pair reduces the possibility of recombination and increased hydroxyl and super oxide ions which are essential oxidizing element used for the improvement of the photocatalytic activity. [48-50].

\section{Conclusions}

In summary g- $\mathrm{C}_{3} \mathrm{~N}_{4}$ based $\mathrm{NiO} / \mathrm{g}-\mathrm{C}_{3} \mathrm{~N}_{4}$ composite was synthesized by facile physical mixing method. The $\mathrm{NiO}$ with $\mathrm{g}-\mathrm{C}_{3} \mathrm{~N}_{4}$ offered high active radical $\left(\cdot \mathrm{O}_{2}{ }^{-}\right)$species and prevented electron/hole pair recombination. As synthesized $\mathrm{NiO} / \mathrm{g}-\mathrm{C}_{3} \mathrm{~N}_{4}$ showed excellent photocatalytic activity of RhB under visible light irradiation as compared with bare $\mathrm{NiO}$ and $\mathrm{g}-\mathrm{C}_{3} \mathrm{~N}_{4}$. The enhanced photocatalytic activity of $\mathrm{NiO} / \mathrm{g}$ $\mathrm{C}_{3} \mathrm{~N}_{4}$ was achieved due to synergistic effect between $\mathrm{NiO}$ and g- $\mathrm{C}_{3} \mathrm{~N}_{4}$.

\section{Declarations}

\section{Acknowledgment}

The authors thanks to SRM Institute of Science and Technology for providing major instrumentation facilities (NRC-SRMIST and HRTEM FACILITY at SRMIST set up with support from MNRE (Project No. 31/03/2014-15/PVSE-R\&D, Government of India).

\section{Conflict of Interest}

No conflict of interest exists.

We wish to confirm that there are no known conflicts of interest associated with this publication and there has been no significant financial support for this work that could have influenced its outcome.

\section{Credit Author Statement}

M.Gayathri: Conceptualization, Data curation, Investigation, Visualization, Writing - original draft.

N.Jayaprakash: Image editing, interpretations, and writing.

E.Sundaravadivel: Project administration and Supervision.

\section{References}

1. Y.N. Rane, D.A. Shende, M.G. Raghuwanish, R.R. Koli, S.R. .Gosavi, N.G.Deshpande, Visible-light assisted CdO nanowires photocatalyst for toxic dye degradation studies. Optik. 179, 535-544 (2019)

2. M. A.Tadjarodi.H.Kerdari Imani, Experimental design to optimize the synthesis of CdO cauliflowerlike nano structure and high performance in photodegradation of various azo dyes. 
3. P. Dhatshanamurthi, B. Subash, M.Shanthi, Investigation on UV-A light photocatalytic degradation of an azo dye in the presence of $\mathrm{CdO} / \mathrm{TiO}_{2}$ coupled semiconductor. Mater.Sci.Semicond.Process. 35, 22-29 (2015)

4. D. D.Battacharya, Gjoshal, D.Mondal, B.K.Paul, N.Bose, S.Das, M.Basu, Visible Light Driven Degradation of Brilliant Green dye using Titanium based ternary metal oxide photocatalyst. RESULTS.PHYS. 12, 1850-1858 (2019)

5. D. C.Debabrata.Shimanta, Visible light induced photocatalytic degradation of organic pollutants. J.Photochem.Photobiol C. 6(2-3), 186-205 (2005)

6. Y. Chen, J. Li, B. Zhai, Y.Liang, Enhanced photocatalytic degradation of RhB by two dimensional composite photocatalyst. Colloid and surf A. 568, 429-435 (2019)

7. S. Vasantharaj, S.S. Mythili, P. Senthilkumar, G. Kavitha, M. Shanmugavel, E. Manikandan, A.Pugazhendi, Synthesis of ecofriendly copper oxide nanoparticles for fabrication over textiles fabtics characterization of antibacterial activity and dye degradation potential. Journal of photochem\& photo biol B. 192, 143-149 (2018)

8. M.A. Rauf, S.Ashraf, Fundamental Principle and application of heterogeneous photocatalytic degradation of dyes in solution. J.Chem.Engg. 151, 10-18 (2000)

9. HanedaHajmine LiD, Morphologies of Zinc oxide nanoparticles and their effects on photocatalysis. Chemosphere. 51(2), 129-137 (2003)

10. A. Fujishima, X. Zhang, D.A. Tryk, $\mathrm{TiO}_{2}$ photocatalysts and related surface phenomena. Surf.Sci.Rep. 63, 515-582 (2008)

11. I.Atkinson, V.Parvulescu, J.P.Cusu, E.M.Anghel, M..D. Voicescu.S. Culita.C. Somacescu.Munteanu, Influence of preparation method and nitrogen $(\mathrm{N})$ doping on properties and photo-catalytic activity of mesoporous $\mathrm{SrTiO}_{3}$. J.photochem\&photobiol A. chem. 368, 41-51 (2019)

12. S. Ghafoor, A. Inayat, F. Aftab, H. Duran, K. Kirchhof, S. Waseem, S.N.Arshad, $\mathrm{TiO}_{2}$ nanofibres embeeded with g- $\mathrm{C}_{3} \mathrm{~N}_{4}$ nanosheets and decorated with Ag nanoparticles as Z-scheme photocaralysts for environmental Remediation. J.Environ.Chem.Engg. 7(6), 103452 (2019)

13. D.Delgadoa, R.Sanchish, J.A.Cecilliac, E.Rodriguez-Castelionc, A.Cabalierod, B.Solsonab, J.M. .Lopez, Support effects on NiO-based catalysts for the oxidative dehydrogenation (ODH) of ethane. Catal.Today. 333, 10-16 (2019)

14. J.Wang, Y.Liu, Z..Wang, P.Wang, Z.Zheng, X..Qin, X.Zhang, Y.Dal, B..Huang, Enhanced photocatalytic activity towards $\mathrm{H}_{2}$ evolution over $\mathrm{NiO}$ Via phosphonic acid surface modification with different functional group. INT.J.HYDROGEN,ENERG. 31(21), 16575-16581 (2019)

15. Y. Bu, Z.Chen, Role of polyaniline on the photocatalytic Degradation and stability performance of the polyaniline/Silver/Silver phosphate composite under Visible Light. Appl.Mater. interface. 6, 1758917598 (2014)

16. L. Ge, Synthesis and photocatalytic performance of novel metal free $\mathrm{g}-\mathrm{C}_{3} \mathrm{~N}_{4}$ photocatalysts. 
17. C. Li, Z. Loua, Y. Yang, Y. Wang, Y. Lu, Z. Ye, L. Zhu, HollowsphereNanohetero junction of g- $\mathrm{C}_{3} \mathrm{~N}_{4}$ @ $\mathrm{TiO}_{2}$ with high visible light photocatalytic property. Langmuir. 35(3), 779-786 (2019)

18. G. Tzvetkov, M. Tzvetkov, T.Spassov, Ammonia-evaporation-induced construction of three dimensional NiO-g- $\mathrm{C}_{3} \mathrm{~N}_{4}$ composite with enhanced adsorption and visible light active driven photocatalyst. Super Lattices Microstru. 119, 122-132 (2018)

19. DifaXu, B.Cheng, W.Wang, C.Jiang, J. Yu, $\mathrm{Ag}_{2} \mathrm{CrO}_{4} / \mathrm{g}-\mathrm{C}_{3} \mathrm{~N}_{4} /$ grapheme oxide ternary composite Zscheme photocatalyst with enhanced $\mathrm{CO}_{2}$ reduction activity. Appl.catal.B:Environ. 231, 368-380 (2018)

20. Y. Beibel Wu, K. Li, L. Su, Tan, X.Liu, Z..Cui, X.Yang, Y.Liang, Z..Li, S.Zhu, K.W.K. .Yeung, Shulin Wu, The enhanced photovatalytic properties of $\mathrm{MnO}_{2} / \mathrm{g}-\mathrm{C}_{3} \mathrm{~N}_{4}$ heterostructure for Rapid sterilization under Visible Light. J.HAZARD.MATER. 337, 227-236 (2019)

21. W. Liu, C. Wang, L. Wang, Photo catalyzed the facile synthesis of \#-chloro aryl ketones with PANI/g$\mathrm{C}_{3} \mathrm{~N}_{4} / \mathrm{TiO}_{2}$ composite under visible ligh. Ind.Eng.Chem.Res. 56(31), 6114-6123 (2017)

22. H.Y. Xu, H.Zhao Li-Cheng, Li-Guolin,Shu-YanQi, Synergic effect brtween adsorption and photocatalysis of metal free $\mathrm{C}_{3} \mathrm{~N}_{4}$ derived from different precursors. PLOS ONE. (2015)

23. L.Williams, A.R.Prasad, P.Sowmya, A.Joshep, Characterization and Temperature dependence DC Conductivity study of Bio template $\mathrm{NiO}$ and their composites using polyaniline. Mater.Chem.phys. 242, 122469 (2019)

24. L. X.Shen.L. Song.Luo, Y.Zhang, J..Z. Liu, L.Zhang, Preparation of $\mathrm{TiO}_{2} / \mathrm{C}_{3} \mathrm{~N}_{4}$ heterojunctions on carbon-fiber cloth as efficient filter-membrane - shaped photocatalyst for removing various pollutanta from the flowing waste water. J.Colloid.Interface Sci. 532, 798-807 (2018)

25. J.X. N.Mao, .Jiang, $\mathrm{MgO} / \mathrm{g}-\mathrm{C}_{3} \mathrm{~N}_{4}$ nanocomposites as efficient water splitting photocatalysts under visible light irradiation. Appl.Surf.Sci. 476, 144-150 (2019)

26. V.V. Anusha, S. Thangarajan, K. Anupriya, B.Subramanian, Functionalization of fabric with PANI-CuO nanoparticles by precipitation route for antibacterial applications. J.Nanopart.Res. 17-57 (2017)

27. C. X.Yuan.Q. Zhon.Jing, Q.Tang, Y.Mu, A.K.Du, Facile synthesis of $\mathrm{g}-\mathrm{C}_{3} \mathrm{~N}_{4}$ nanosheets/Zno nanocomposites with enhanced photocatal photocatalytic activity in reduction of aqueous chromium (VI) under visible light. Nanomaterials. 6, 173 (2016)

28. E. Y.Hang.J. Liu.Shi, X.Lin, L.Sheng, M..L. Zhang.J. Wang.Chen, A direct one step synthesis of ultrathin $\mathrm{g}-\mathrm{C}_{3} \mathrm{~N}_{4}$ nanosheets from thio urea for boosting solar photocatalytic. Int.J.Hydrogen.Energ. $\mathrm{H}_{2}$ evolution. 44(14), 7194-71204 (2019)

29. S. Mahalingam, Y. Ahn, Improved visible light photocatalytic activity of $\mathrm{rGo} / \mathrm{Fe}_{3} \mathrm{O}_{4} / \mathrm{NiO}$ hybrid nanocomposites synthesized by insitu facile method for industrial waste water treatment applications. J.New.Chem. 42, 4372-4383 (2018)

30. S.M. Aydoghmish, S.A. Hassanzadeh-Tabrizi, A. Saffar-Teluri, Facile synthesis and investigation of NiO-ZnO-Ag nanocomposites as efficient photocatalysts for degradation of methylenr blue dye.. 
31. S. Kulkarni, M. Jadhav, P. Raikar, S. Raiker, U.S.Raiker, Core-shell novel composite metal nanoparticles for hydrogenation and dye degradation applications. Ind.Eng.Chem.Res. 58(9), 3630-3639 (2019)

32. Z. Wei, H. Qiao, H. Yang, C. Zhang, X.Yan, Characetrization of NiO nanoparticles by anodic arc method. J.Alloys.comp. 479, 855-858 (2009)

33. L. Tan, J. Xu, X. Zhang, Z. Hang, Y. Jia, S.Wang, Synthesis of $\mathrm{g}-\mathrm{C}_{3} \mathrm{~N}_{4} / \mathrm{CeO}_{2}$ nanocomposites with improved catalytic activity on the thermal decomposition of ammonium perchlorate. Appl.Surf.Sci. 356, 447-453 (2015)

34. J.Y. Tang, R.T. Guo, W.G. Zhou, C.Y. Haung, W.G. Pan, Ball-flower like NiO/g- $\mathrm{C}_{3} \mathrm{~N}_{4}$ heterojunction for efficient visible light photocatalytic $\mathrm{CO}_{2}$ reduction. Appl.catal.B.Eniviron. 237, 802-810 (2018)

35. P.E. Saranya, S.Selladurai, Mesoporous 3D network Ce doped NiO nanoflakes as high performance electrodes for supercapacitor applications. New.J.Chem. 43, 7441-7456 (2019)

36. K. X.CWang.A.Thomas Maeda, K. Takanabe, G. Xin, J.M. Carlsson, K. Domen, M.Antonietti, A metal free polymeric photocatalyst for hydrogen production from water under visible light. Nat.Mater. 8(1), 76-80 (2009)

37. P. Singh, C.S. Kushwaha, S.K. Shukula, G.C.Dubey, Synthesis and Humidity sensing properties of NiO intercalated polianiline Nanocomposite. POLM.PLAS TECH \&ENGG. 58(2), 139-147 (2018)

38. K.Ngeyun, N.D.Hoa, C.M.Hung, D.T.T..Le, N.V.Duy, N.V. .Hiau, A comparative study on the electrochemical properties of nanoporous nickeloxide nanowire and nano sheets prepared by hydrothermal method.. RSC Adv. 8, 19449-19455 (2018)

39. J.Singh, A.Arora, S.Basu, Synthesis of $\mathrm{WO}_{3} / \mathrm{g}-\mathrm{C}_{3} \mathrm{~N}_{4}$ nanocomposites for the removal of hazardeous dyes under visible light. J.Alloys.Comp. 808, 151734 (2019)

40. Y. Zhan, Z. Liu, Q. Liu, D. Huang, Y. Wei, Y. Hu, X.Liana,C. Hu, A facile and one pot synthesis of fluorescent graphitic carbon nitride quantum dots for bio imaging application. New.J.Chem. 41, 3930-3938 (2017)

41. C.J. Mathai, S. Saravanan, M.R. Anantharaman, S. Venkatachalam, S.Jeyalakshmi, Effect of lodine doping on the bandgap of plasma polymerized aniline thin films. J.Phys.D.Appl.Phys. 35, 22062210 (2002)

42. H. Chen, S. Wageh, A.Ahmed Al-Ghamdi, H. Wang, J. Yu, C.Jiang, Hierarchial C/NiO-ZnO nanocomposite fibers with enhanced adsorption capacity for congo red. J.Colloid Interfac.Sci. 537, 736-745 (2019)

43. Y. Fu, C. Liua, C. Zhua, H. Wanga, Y. Doub, W. Shia, M. Shaoa, H. Huango, Y. Liua, Z.Kanga, Highperformance $\mathrm{NiO} / \mathrm{g}-\mathrm{C}_{3} \mathrm{~N}_{4}$ composites for visible-light-driven photocatalytic overall water splitting. Inorg. 00, 1-3 (2013)

44. H.Y. Chen, L.G. Qiu, J.D. Xiao, S. Ye, X. Jing, Y.Peng Yuan, Inorganic-Organic hybrid NiO-g- $\mathrm{C}_{3} \mathrm{~N}_{4}$ photocatalyst for efficient methylene blue degradation using visible light. RSC Adv. 4, 22491-22496 (2014) 
45. W. X.Ning.X. Zhen.G. Zhang.Lu, Significant enhancement of stability for visible photocatalytic overall water aplitting by assembling ultra-thin layer of $\mathrm{NiO}$ over Zn1-xCdxS, chemsuschem, 12(7),12671477 (2019)

46. K.Maniammal, G.Madhu, V.Biju, Nanostructured meoporousNiO as an efficient photocatalyst for degradation of methylene blue: Structure, properties and performance. J.Nanostructur. 16, 266-275 (2018)

47. A. Akhundi, A.H. Yangjeh, A simple large scale method for preparation of g- $\mathrm{C}_{3} \mathrm{~N}_{4} / \mathrm{SnO}_{2}$ nanocomposite as visible-light driven for degradation of an organic pollutant. Mater.Express. 5(4), 309-317 (2015)

48. M.A. Alenizil, R. Kumar, M. Aslam, A. Alseroury, M.A. Barakat, Construction of ternary g$\mathrm{C}_{3} \mathrm{~N}_{4} / \mathrm{TiO}_{2} / \mathrm{PANI}$ nanocomposite for the enhanced photocatalytic activity under solar light. Sci.Rep. 9, 12091 (2019)

49. K.H. Rahman, A.K. Kar, Effect of band gap variation and sensitization process of polyaniline PANI$\mathrm{TiO}_{2} \mathrm{p}$-n heterojunction photocatalytic degradation of toxic methylene blue with UV irradiation. J.Environ chem Engg. 8(1), 104181 (2020)

50. K. Yao, Y. Li, H. Yang, J.Yuan, Polyaniline-modified 3D spongy SnS composites for enhanced visiblelight photocatalytic degradation of methyl orange. Colloids.Surf.A. 603, 125240 (2020)

\section{Figures}




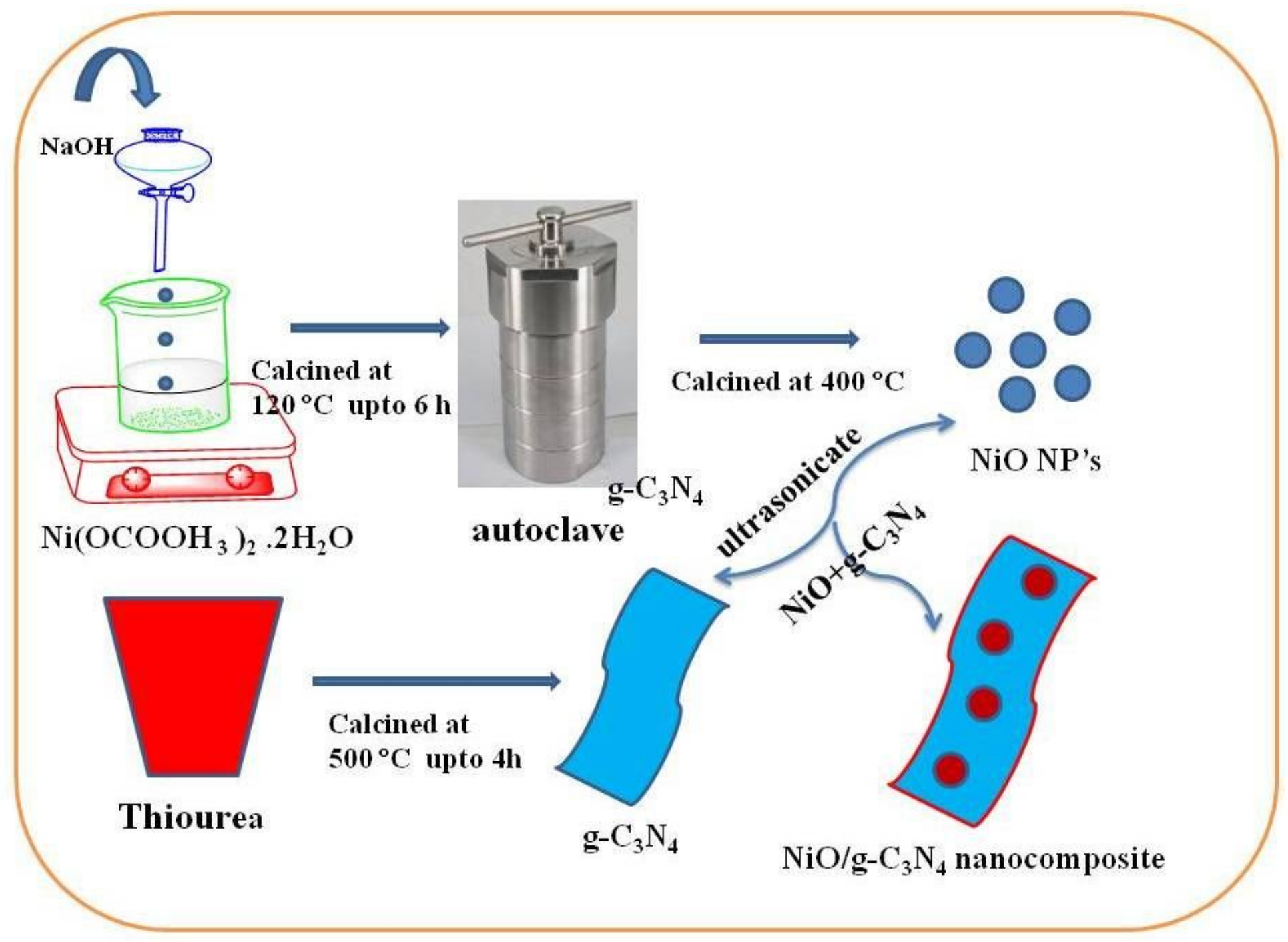

Figure 1

Schemmatic representation of $\mathrm{NiO} / \mathrm{g}-\mathrm{C} 3 \mathrm{~N} 4$ nanocomposite
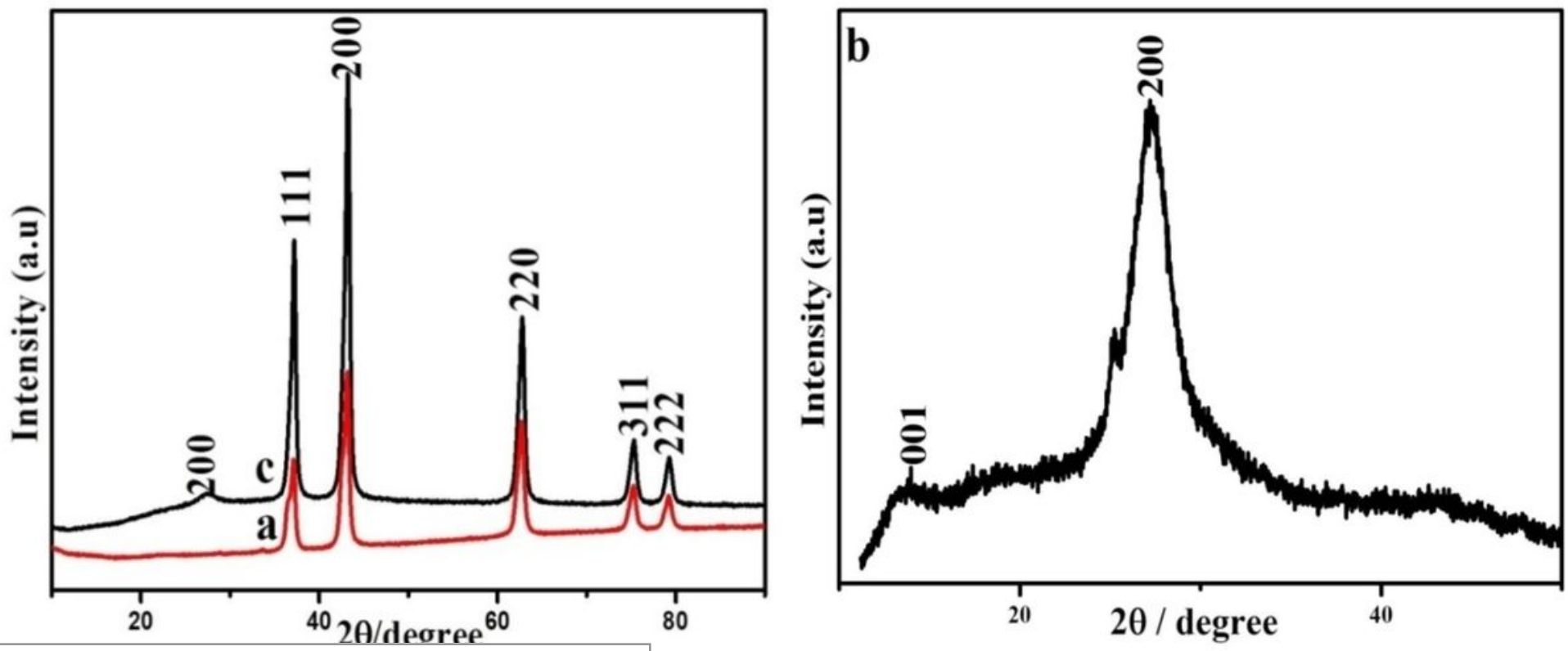

Loading [MathJax]/jax/output/CommonHTML/jax.js 
Figure 2

XRD pattern of (a) bare NiO, (b) g-C3N4 and (c) NiO/g-C3N4

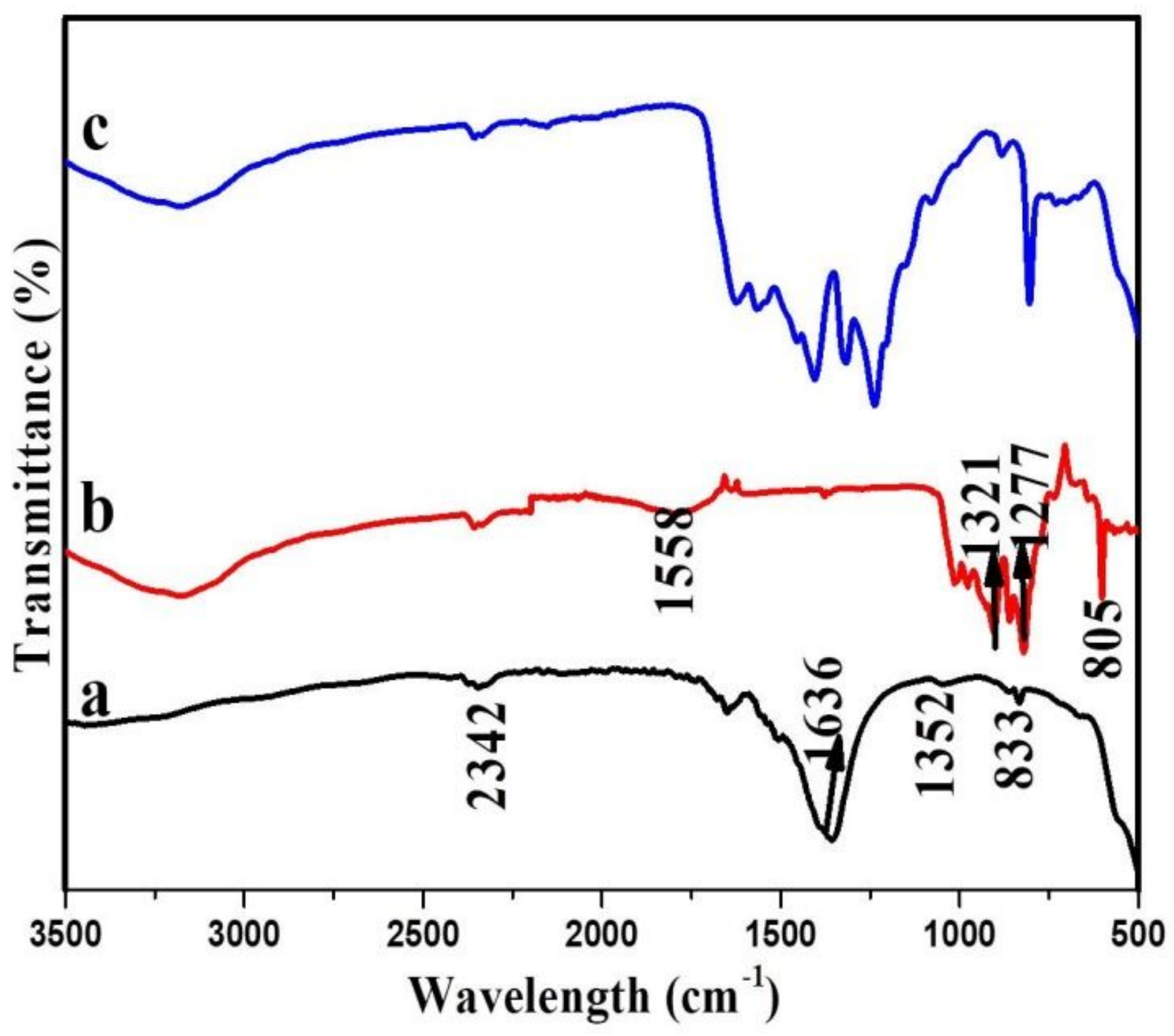

Figure 3

FTIR spectrum of (a) bare NiO, (b) g-C3N4 and (c) NiO/g-C3N4 

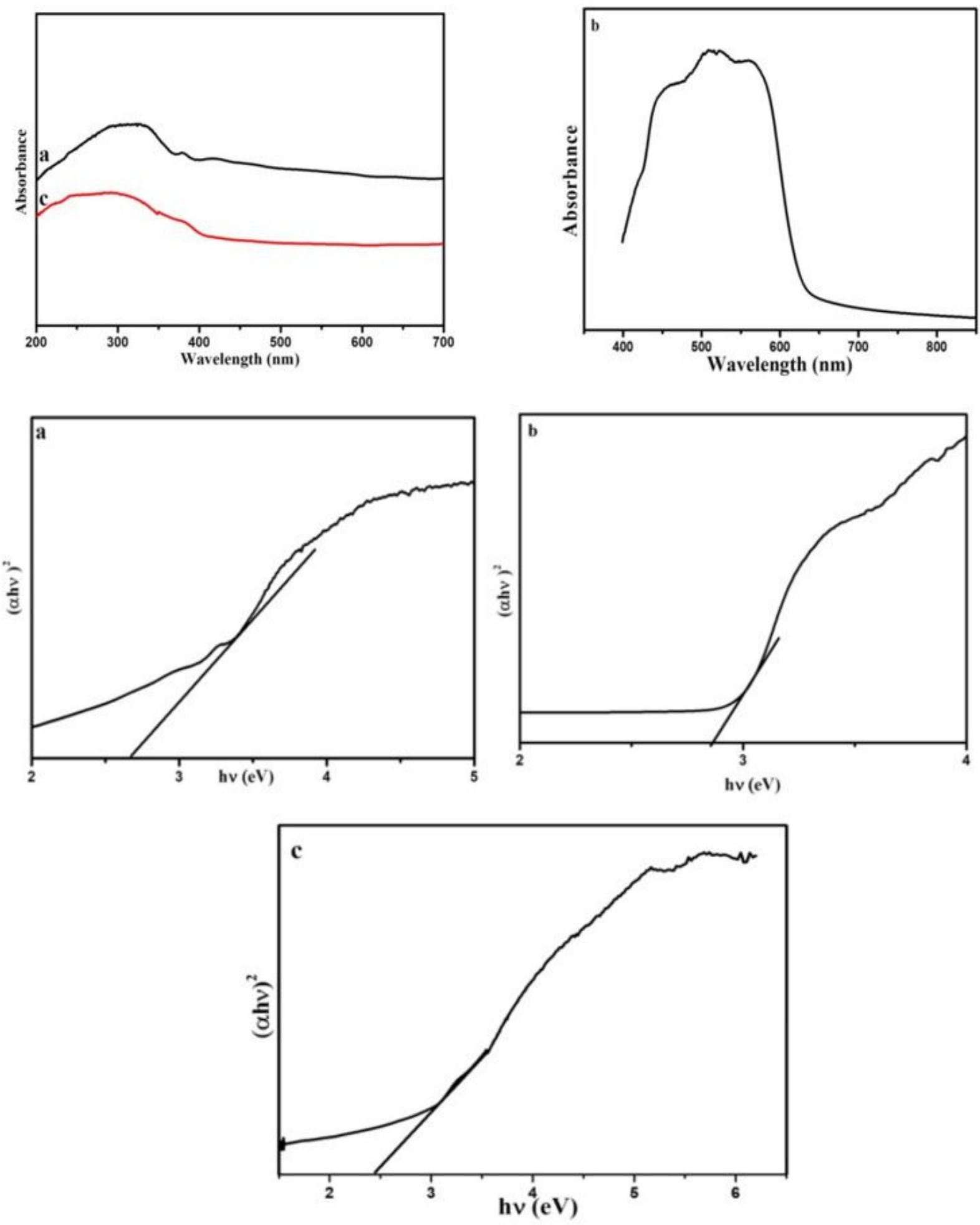

Figure 4

(A)Uv-DRS spectrum of (a) bare NiO, (b) bare g-C3N4 (c) NiO/ g-C3N4 (B) Tauc's plot of (a) bare NiO, (b) bare g-C3N4 (c) NiO/ g-C3N4 

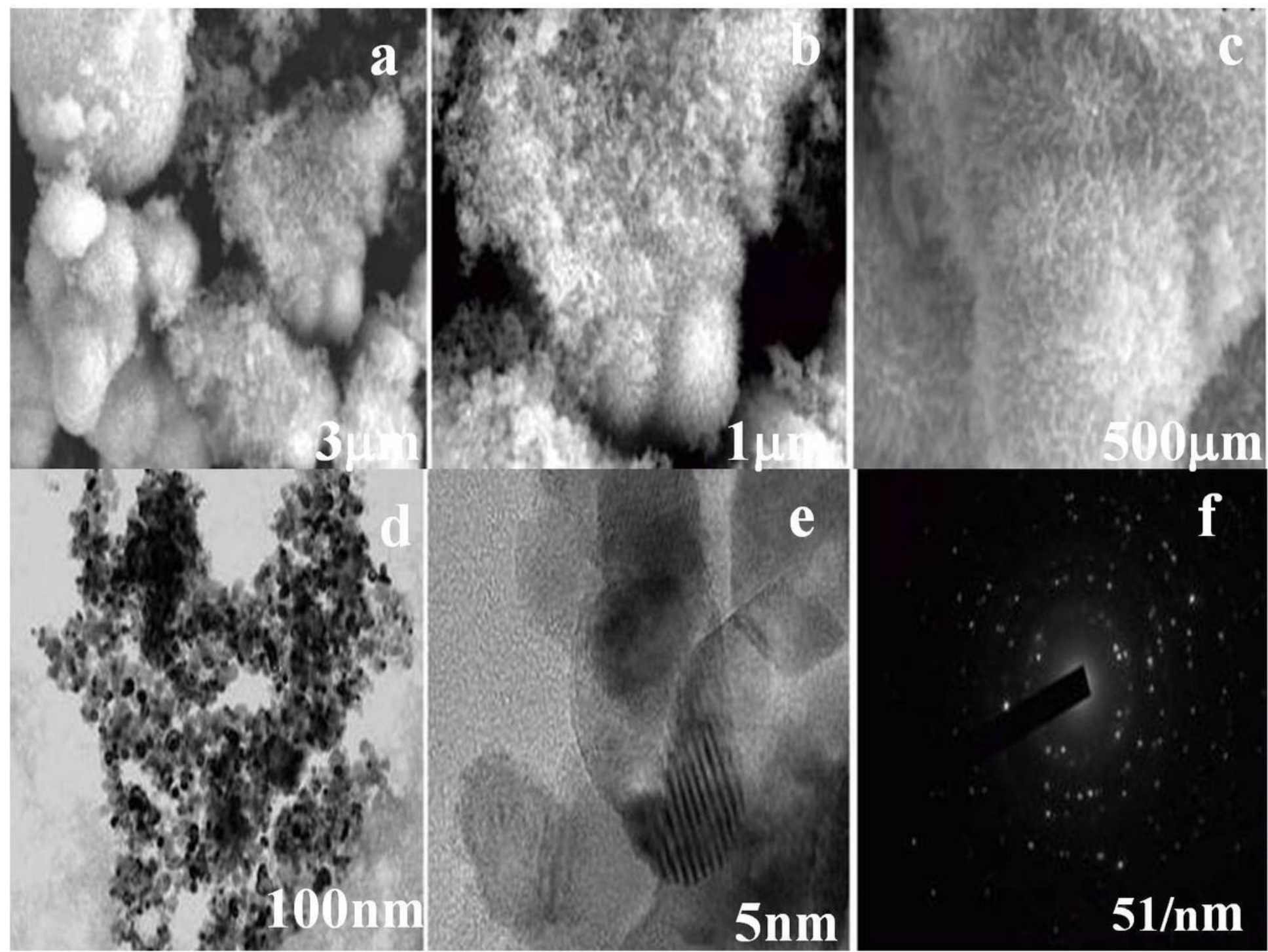

\section{Figure 5}

(a-c) SEM images of bare NiO, (d,e) TEM images of bare NiO, (f) SAED pattern of bare NiO. 

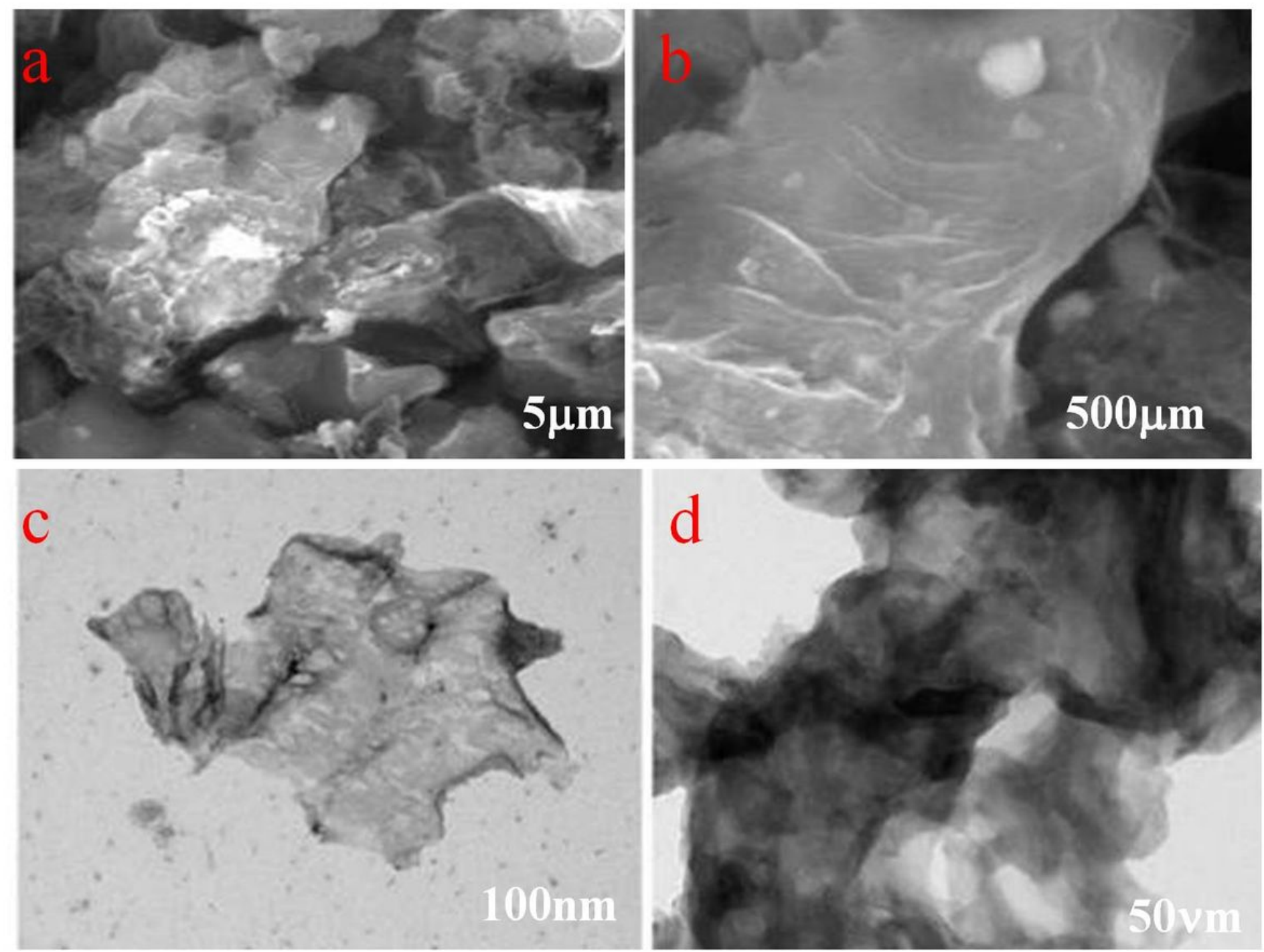

Figure 6

$(a, b)$ FESEM images of bare g-C3N4(c,d) HRTEM images of bare g-C3N4 


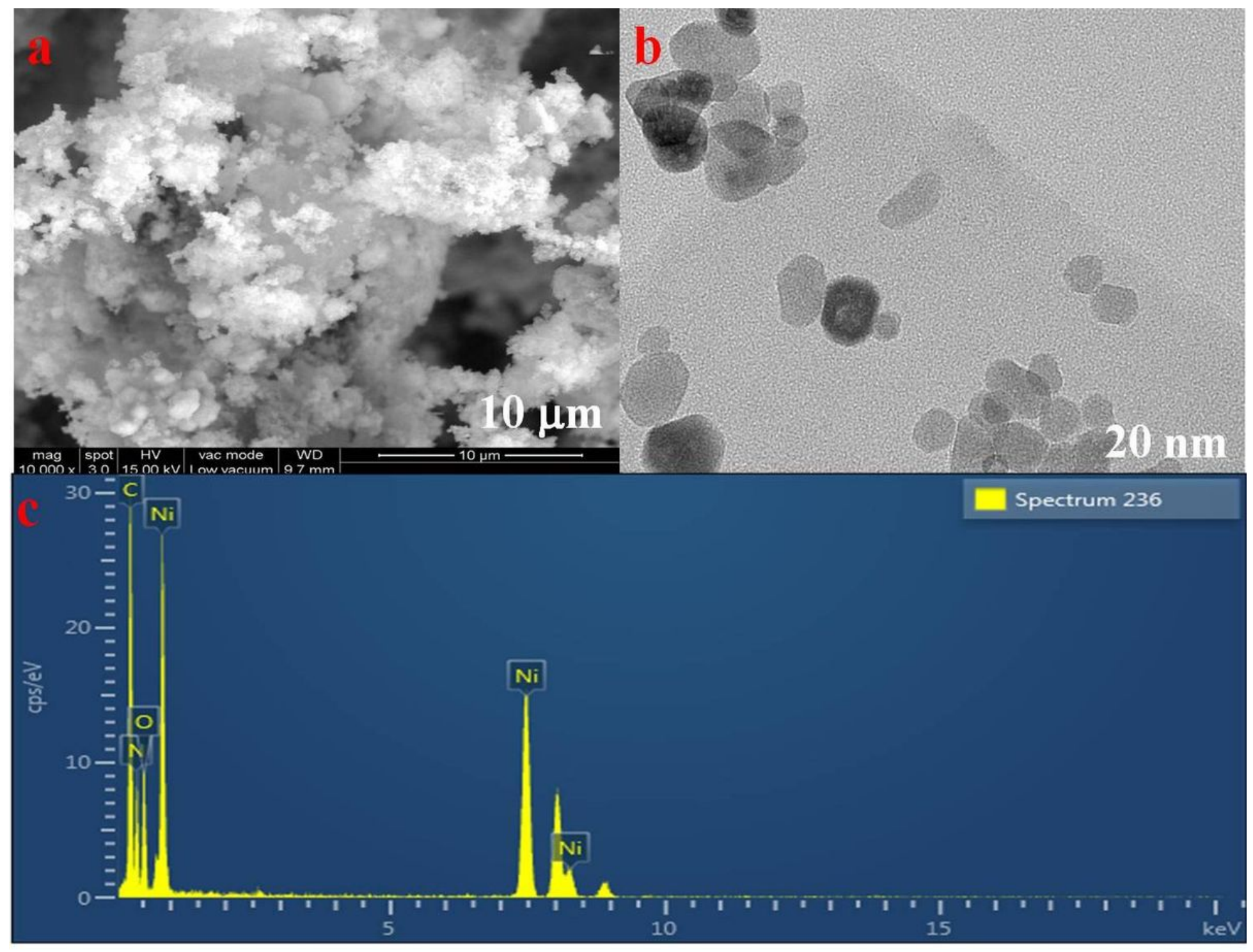

Figure 7

(a) FESEM image of NiO/g-C3N4, (b) HRTEM image of NiO/g-C3N4, (c) EDX spectrum of NiO/g-C3N4.
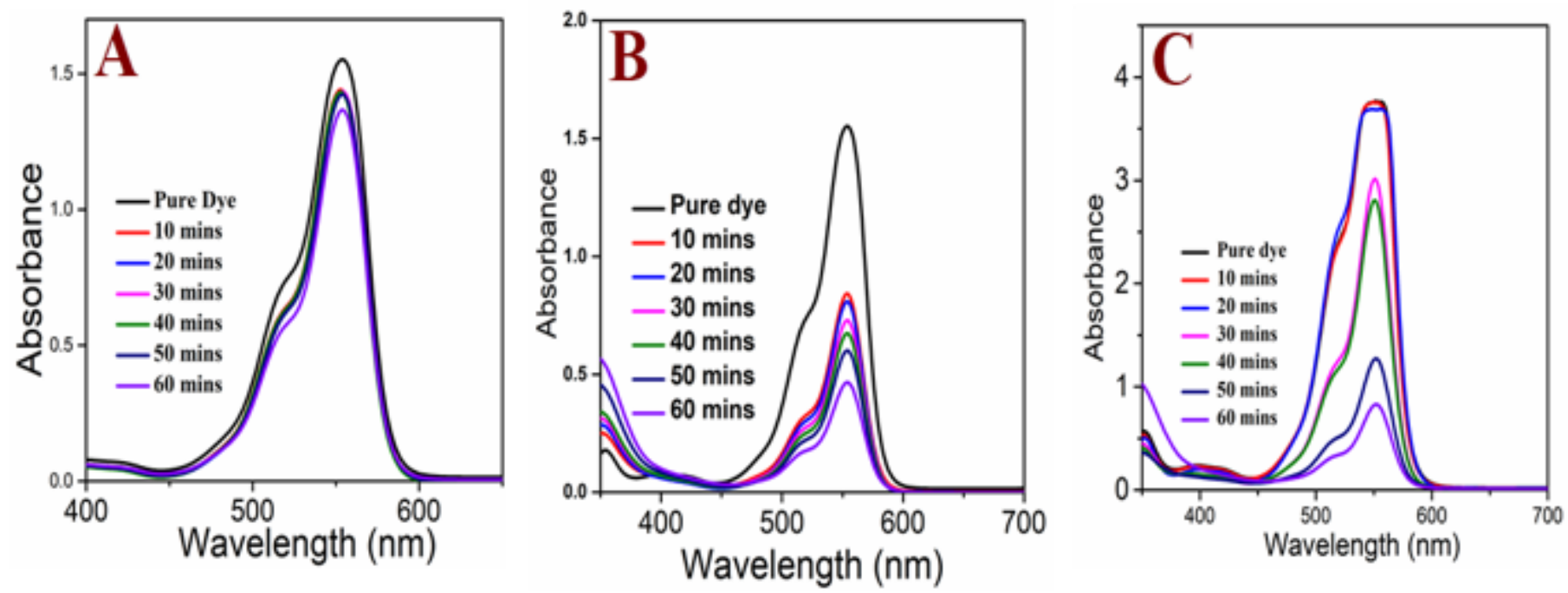
Figure 8

Absorbance spectrum of RhB using (A) bare NiO, (B) bare g-C3N4, (C) NiO/C3N4

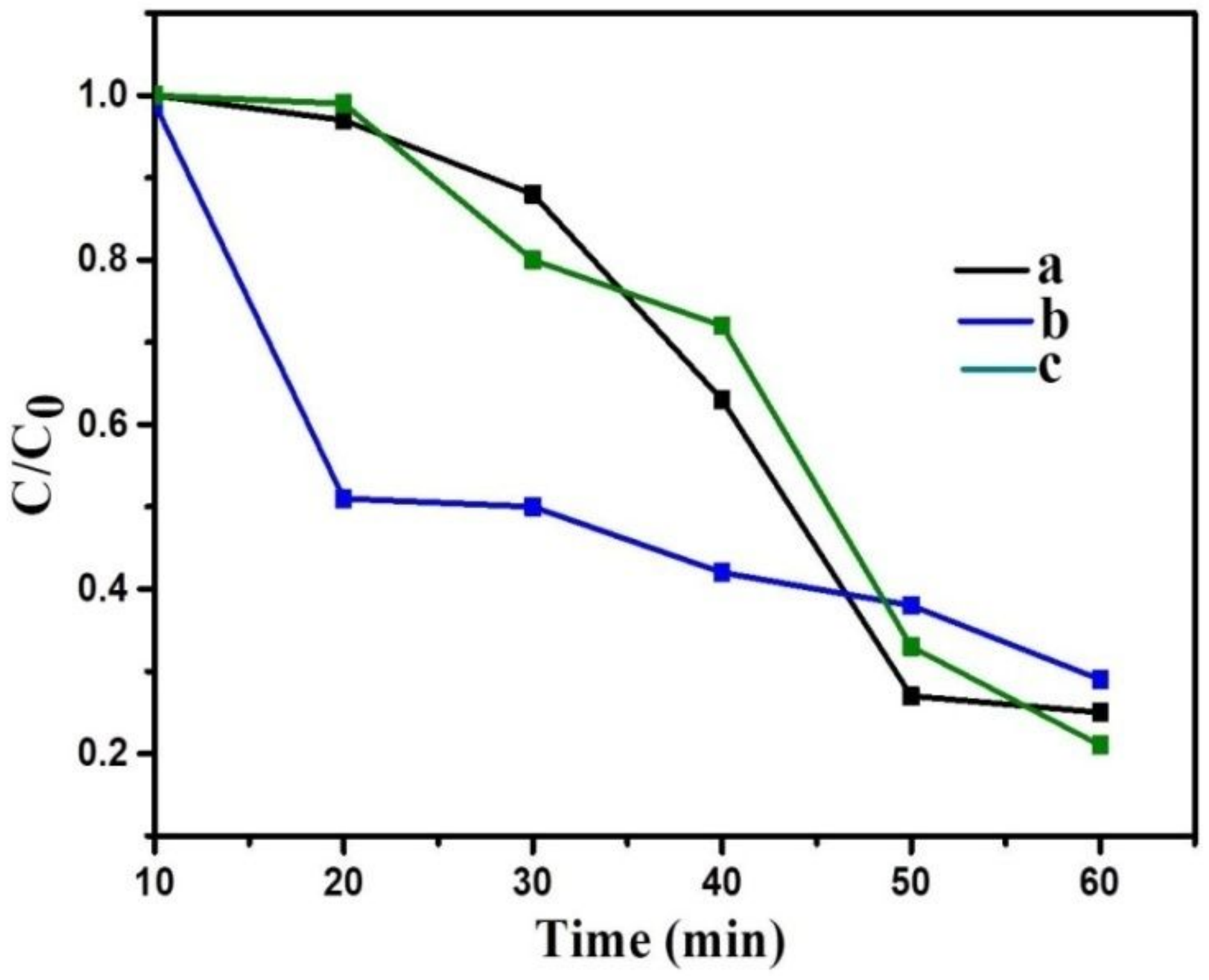

Figure 9

Plots of C/Co and InC/Co vs time under visible light irradiation using (a) Bare NiO, (b) bare g-C3N4, (c) $\mathrm{NiO} / \mathrm{g}-\mathrm{C} 3 \mathrm{~N} 4$ 